\title{
Drug Development, Preclinical
}

National Cancer Institute

\section{Source}

National Cancer Institute. Drug Development, Preclinical. NCI Thesaurus. Code C15801.

Drug development activites focused on preclinical trials and testing. 